\title{
La casa del vecino. Tipos y evolución en la arquitectura doméstica tradicional del Guadiana portugués
}

\author{
Ana Costa Rosado | Centro de Estudos em Arqueologia, Artes e Ciências do \\ Património \\ María Teresa Pérez Cano | Dpto. de Urbanística y Ordenación del Territorio, \\ Universidad de Sevilla \\ Miguel Reimão Costa | Centro de Estudos em Arqueologia, Artes e Ciências do \\ Património \\ URL de la contribución <www.iaph.es/revistaph/index.php/revistaph/article/view/4734>
}

\section{RESUMEN}

La arquitectura doméstica refleja, mejor que ninguna otra, la cultura de un lugar, las costumbres, las vivencias de sus gentes. Se rige por las directrices de su territorio, los terrenos, los materiales, los condicionantes climáticos $y$, por eso, ni puede ser estudiada fuera de su contexto, ni el paisaje de un lugar se explica sin su arquitectura vernácula. Pero ¿y cuándo de un mismo territorio físico resultan modelos dispares? Este artículo revisa la casa tradicional del Alentejo portugués, concretamente, el margen izquierdo del Guadiana, a través de levantamientos in loco y el estudio de documentación de archivo. Se presenta como caso de estudio la ciudad de Moura, donde el análisis de 143 casos ha permitido establecer una línea de evolución de la vivienda y definir varias categorías de tipos de casa tradicional. Se presentan estos tipos, sus materialidades, las técnicas constructivas de la región y una similitud transfronteriza. Si por el mismo contexto histórico y territorial, las afinidades de ocupación territorial y urbana entre el Guadiana portugués y la Baja Extremadura/Sierra de Aracena resultan casi obvias, resultarán más sorprendentes las diferencias que experimentará la evolución de la vivienda entre los dos márgenes del Guadiana.

\section{Palabras clave}

Arquitectura tradicional | Casa urbana | Construcción vernácula | Alentejo (Portugal) | 


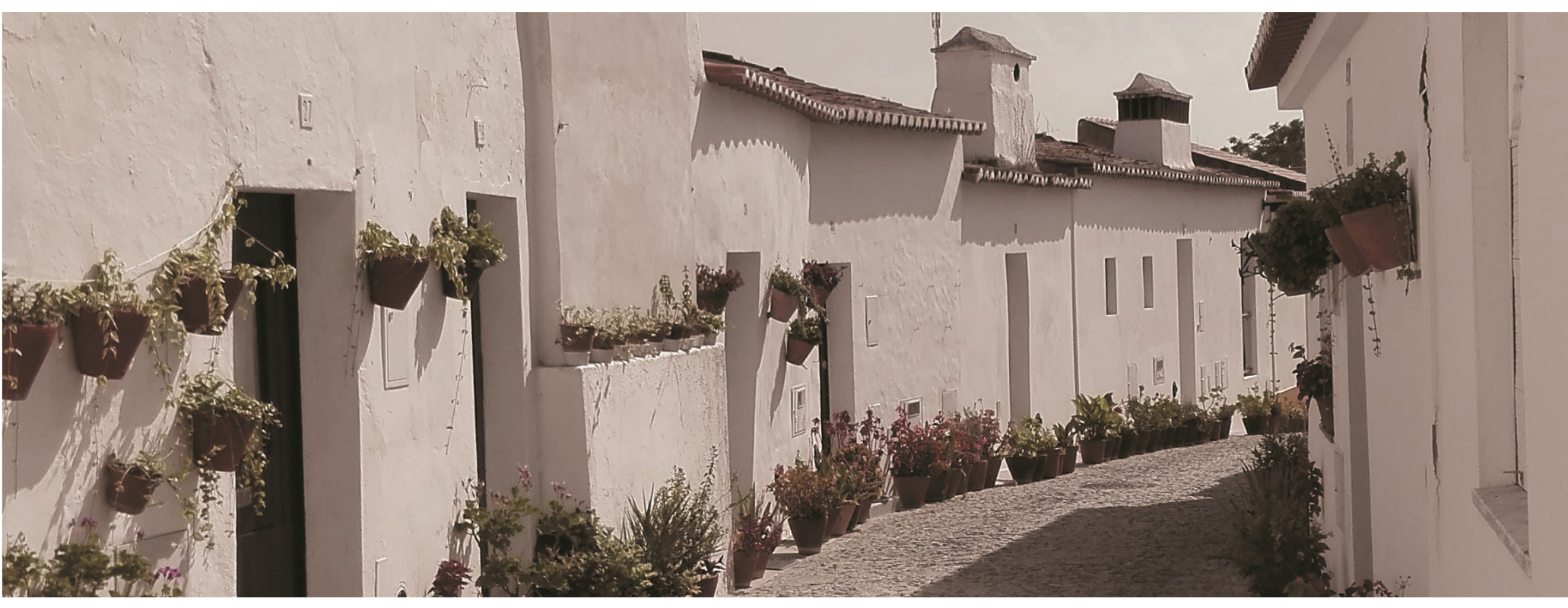

\section{The neighbour's house-types and evolution in traditional housing architecture of Portuguese Guadiana}

\section{ABSTRACT}

Domestic architecture is the one that best reflects the culture of a given place, its traditions and the everyday life of its people. Common housing follows the guidelines of its surroundings, the territory, materials, and climate conditions. Therefore, it cannot be studied apart from its context, nor a territorial unit can be explained without its vernacular architecture. But what if one same physical territory produces different housing models? This paper studies traditional housing types in the Portuguese Alentejo, specifically in the Guadiana's left bank, through architectonic surveys and archive documentation. The case study is the city of Moura, where it was possible -through the analysis of 143 houses- to establish a housing evolution line and to define categories of housing types. The article presents the mentioned types, their materiality, their constructive techniques and one cross-border similarity. It is to notice that, given the fact that Portuguese Guadiana and Lower Extremadura are under the same territorial and -until the 13th century- historical contexts, urban similarities between them are profound. It is almost surprising how divergent housing evolution between the two will become.

\section{Keywords}

Traditional architecture | Urban housing | Vernacular construction | Alentejo (Portugal) |

Cómo citar: Rosado, A.C., Pérez Cano, M. ${ }^{a}$ T. y Reimão Costa, M. (2021) La casa del vecino. Tipos y evolución en la arquitectura doméstica tradicional del Guadiana portugués. Revista $\mathrm{PH}, \mathrm{n} .^{\circ}$ 102, pp. 56-77. Disponible en: www.iaph.es/revistaph/index.php/revistaph/article/view/4734

DOI 10.33349/2021.102.4734

Enviado: 24/07/2020 | Aceptado: 03/12/2020 | Publicado: 10/02/2021 


\section{INTRODUCCIÓN}

Siguiendo hacia el oeste de Andalucía, más allá del occidente de Sierra Morena, nos encontramos, sin apenas percibirlo, en la región portuguesa del Alentejo. A pesar de que en nuestro mapa mental surja como un lugar distante y apartado, son más las continuidades territoriales que las roturas. El Guadiana, a veces incumbido de convertir en real la línea imaginaria que divide este territorio, es hilo conductor de una misma unidad territorial, caracterizada por un relieve suave de penillanura y un paisaje marcadamente agrícola, con grandes áreas de dehesa. El valle del Guadiana, anteriormente unido en la provincia romana de Lusitania y la región de al-Gharb en época de Al-Ándalus, se fraccionaría bajo dos administraciones antes del final del siglo XIII. Esta separación de siglos supuso marcadas diferencias en la vida cotidiana de las gentes a ambos lados de la frontera, que son hoy especialmente visibles en los espacios construidos, y, sobre todo, en la casa.

Este artículo presenta parte de un análisis tipológico de la casa vernácula urbana de Alentejo, concretamente de la margen izquierda del Guadiana, integrado en los contextos territorial y urbano de la región, así como en la materialidad de la construcción. Aunque formal y constructivamente similar a las casas de la Sierra de Aracena, la casa alentejana a oriente del Guadiana se materializa en tipos y formas de organización del espacio sin paralelismos a la vivienda del otro lado de la frontera. El estudio de la arquitectura doméstica alentejana es especialmente interesante para la historia de la vivienda al reflejar cómo pueden divergir las costumbres y, consecuentemente, los modelos habitacionales en una sociedad que parte de un mismo punto común y se divide administrativamente.

Se presenta como caso de estudio la ciudad de Moura, ubicada en la margen izquierda del Guadiana. Se analiza la evolución de su arquitectura doméstica, los tipos habitacionales encontrados y sus técnicas constructivas, además de compararlos con los casos vecinos de la Sierra de Aracena. La casa tradicional se encuentra hoy bajo grave amenaza de desaparición al haber sido, durante el último medio siglo, considerada inapropiada para las necesidades habitacionales contemporáneas a causa del cambio de funciones de la casa, la especialización de los compartimientos y una mayor exigencia de privacidad. Los cambios impuestos por una nueva concepción del modo de habitar suponen una urgencia en el registro de la casa tradicional antes de su inevitable e inminente pérdida.

La investigación que da origen a este artículo se basa en el levantamiento arquitectónico de casas en dos zonas distintas de Alentejo para permitir un análisis comparativo. Son estudiadas las ciudades alentejanas de Estremoz, Borba (Alentejo norte/central), Moura y Serpa (Alentejo sur). En Moura han sido recogidos los datos de 143 casos de estudio, mediante levantamientos 


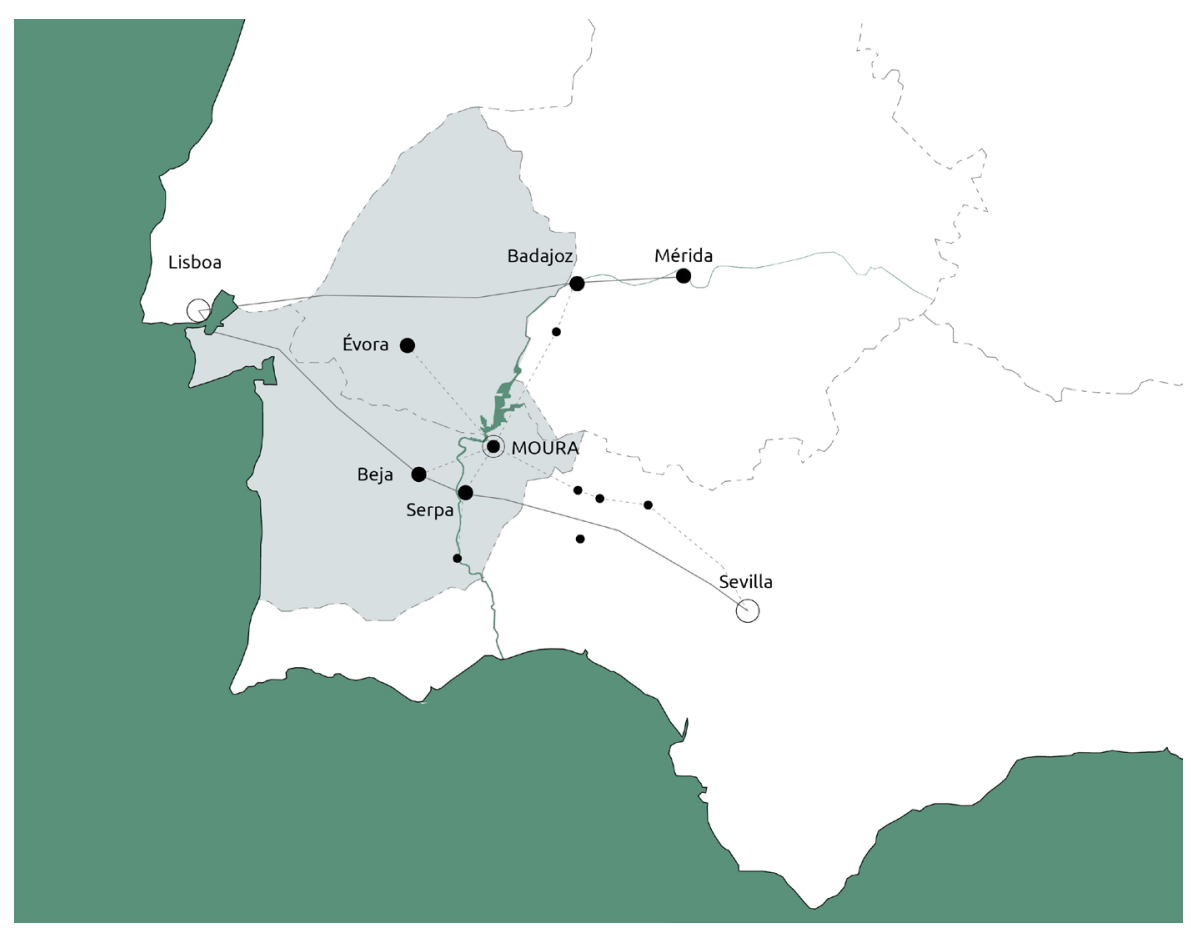

Localización de Moura y del Alentejo en el sudoeste peninsular | dibujo Ana Costa Rosado, María Teresa Pérez Cano, Miguel Reimão Costa

in situ y obtención de información de archivo de "processos de obra" en el ayuntamiento-Câmara Municipal. Los "processos de obra" son documentos necesarios para la autorización de obras particulares y muestran el estado anterior y posterior a la transformación del inmueble, lo que permite encontrar las tipologías corrientes a mitad del siglo XX y los cambios experimentados. Estos empiezan a utilizarse a partir del año de 1940, aunque más frecuentemente a partir de los años 70, y posibilitan seguir las transformaciones más solicitadas en cada época registrada. A los levantamientos arquitectónicos se suma el registro fotográfico de las casas y las entrevistas a sus habitantes, además de información de archivo histórico, tales como escrituras de la propiedad existentes en los Archivos Distritales portugueses.

\section{ALENTEJO: OCUPACIÓN TERRITORIAL Y REALIDAD URBANA}

"(...) pode dizer-se que a região a Oriente do Guadiana relativamente às povoações extremenhas, se coloca num paradoxo. Por um lado, existe uma similitude geo-física e económica e por outro está separada delas por uma linha artificial que predispõe à ruptura" (Cosme 2000, 84).

El alentejano margen izquierdo del Guadiana, tal como las vecinas zonas del Andévalo, Sierra de Aracena y Baja Extremadura, se distingue por su riqueza agrícola. Tiene un paisaje de penillanura de altitudes medias entre los 100 
y 500 m y tierras de calizas rojizas. La orografía suave aliada al clima mediterráneo -Csa en la clasificación climática de Köppen- lo hacen ideal para el cultivo de olivo, que se presenta aquí en gran extensión. Este tipo de producción agrícola genera un parcelario con divisiones de medianas a grandes dimensiones, con raíces en la malla de propiedad romana (Abreu, Correia y Oliveira 2002, 79). Consecuentemente, las aglomeraciones urbanas se distribuyen de forma dispersa por el territorio para liberar el máximo espacio de cultivo. Igualmente presentan formas muy compactas y densas de población que son geométricamente regulares en zonas de llanura (véase Serpa). Más allá del paisaje, sería el establecimiento de la frontera entre Portugal y Castilla-León en el siglo XIII (la fecha probable de ocupación de Moura y Serpa es 1230) (Boiça 2018, 149) que determinaría la distribución de los poblados y la jerarquía de la red urbana alentejana, volcada en esas fechas a las zonas más interiores del territorio, situación diametralmente opuesta a lo que sucede en la actualidad. Como hace notar J. M. Feria para el territorio vecino del Andévalo:

"la tensión hegemónica aparece marcada por la existencia de la frontera luso-castellana desde los primeros momentos de la presencia cristiana, durante la primera mitad del siglo XIII. La misma, conlleva una dicotomía entre la necesidad de poblar el espacio fronterizo y la concurrencia de factores que tienden a la expulsión y despoblación del mismo, fundamentalmente por el carácter negativo de lo inseguro del mismo, resultado de la fricción latente entre las dos coronas." (Feria Toribio, Andrades y Ruiz Recco 2002, 51).

Con el avance de la conquista cristiana, la corona portuguesa impulsaría la creación de nuevos burgos en el Alentejo fronterizo, tanto para defensa territorial como por la necesidad administrativa en ocupar zonas de baja densidad. La morfología de esas nuevas urbes se vería determinada por la condición de frontera: su génesis se basaba en la fortificación de las cimas de elevaciones estratégicas. Los constantes requisitos defensivos a lo largo del tiempo se traducirían en series de líneas defensivas, murallas y baluartes que marcan distintas fases de expansión urbana. Dichos poblados compartirían en su origen una serie de reglas urbanísticas inspiradas en las bastides francesas y que hoy son entendidas como "urbanismo portugués medieval" (Gaspar 1969, 207). Más allá de la ubicación y fortificación, estas directrices urbanísticas incluían una estructura urbana anclada en un eje axial lineal -rua direita- que une las dos puertas del recinto amurallado, con dimensiones de calles y solares predeterminados y jerarquizados.

Algunos de estos aspectos son comunes a la Sierra de Aracena, en concreto a la banda gallega, como la organización territorial dispersa con poblados densos (Feria Toribio, Andrades y Ruiz Recco 2002, 41), fortificados y emplazados en puntos altos de importancia geoestratégica. Tal como ocurriría en Alentejo, los núcleos urbanos crecerían fuera de las murallas, ladera 
abajo, estructurados en los caminos principales (Feria Toribio, Andrades y Ruiz Recco 2002, 47). Las semejanzas no son casuales. La separación efectiva del territorio ubicado sobre la antigua ruta Hispalis-Pax Julia, y que se mantiene polarizado entre Sevilla y Beja, queda indefinida hasta el siglo XVI. La fortificación del territorio se hace de forma espejada a los dos lados de la división en el río Chanza, oponiéndose los núcleos fronterizos de Aroche, Cortegana, Aracena y El Cerro del Andévalo a Mourão, Moura y Serpa, en el Alentejo situado a oriente del Guadiana. Mientras, las disputas son frecuentes, pero también los intercambios comerciales, migraciones y relaciones familiares (Cosme 2000, 92), ya que seguirán en uso los antiguos caminos.

Si, teniendo el mismo contexto territorial y -hasta cierto momento- histórico, las afinidades de ocupación territorial y urbana resultan casi obvias, lo notable serán las diferencias que tomará la evolución de la vivienda entre los dos márgenes del Guadiana.

\section{LA CIUDAD DE MOURA}

Observando el caso de la ciudad de Moura, sobresalen las características urbanas previamente mencionadas para este conjunto de poblaciones. Su núcleo original se encuentra situado en un punto alto, implantado a escasos 4 km del Guadiana y rodeado por murallas, cuyos lienzos más antiguos son tapiales del periodo almohade. La vila se mantiene intramuros hasta su plena integración en el reino portugués en 1295, pero a partir de inicios del siglo XIV el castillo es progresivamente abandonado por sus habitantes (Macias 1993, 135) y a día de hoy no quedan vestigios del tejido urbano intramuros. Los moradores se desplazarían hacia dos arrabales extramuros surgidos poco después de la pacificación de la zona, dejando que el castillo se convirtiera progresivamente en espacio marcadamente militar y administrativo.

El primer arrabal aparece inmediatamente después de la llegada de los cristianos al poder. Es la mouraria, la que albergará a los moros expulsados del núcleo amurallado. Se ubica al suroeste del castillo y se constituye por cuatro manzanas estrechas y largas, divididas en parcelas también estrechas y largas, de gran regularidad, lo que revela una planificación previa. El segundo arrabal, ocupado por cristianos y con carácter comercial, se desarrollará anclado a la carretera hacia Aroche ${ }^{1}$, al este del castillo. Este hecho demuestra la importancia de la ligación transfronteriza ya que ni el camino hacia Beja -la gran urbe más cercana- ni el camino hacia Serpa, con una orientación solar ventajosa hacia el sur, han fijado edificaciones de la misma forma. También aquí se encuentran parcelas estrechas y largas, aunque integradas en manzanas más irregulares que las de la mouraria, denotando una ocupación más orgánica del lugar.
Aroche, en su turno, tiene una de las tres puertas de su muralla orientada a Moura (plan de 1735) (Duclos Bautista 2005), ubicándose en esa puerta el término de la carretera que estructura este arrabal. 


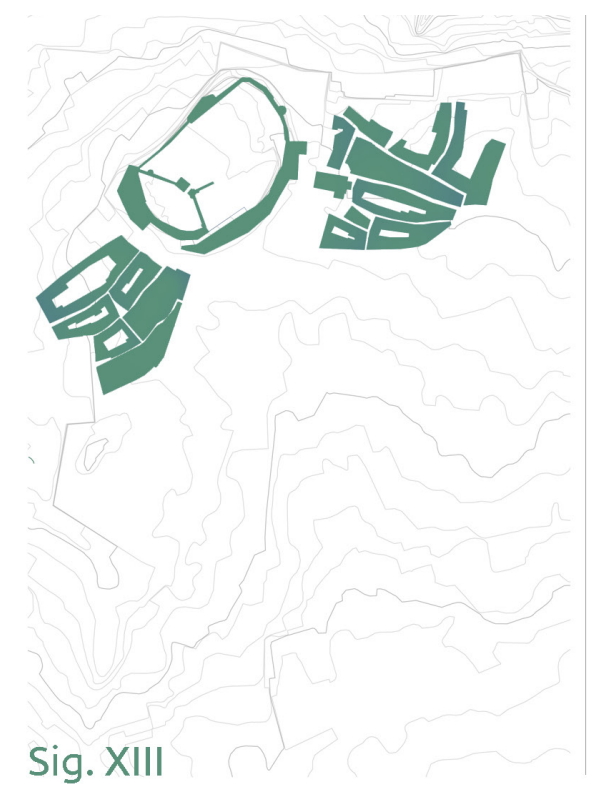

Evolución urbana de Moura
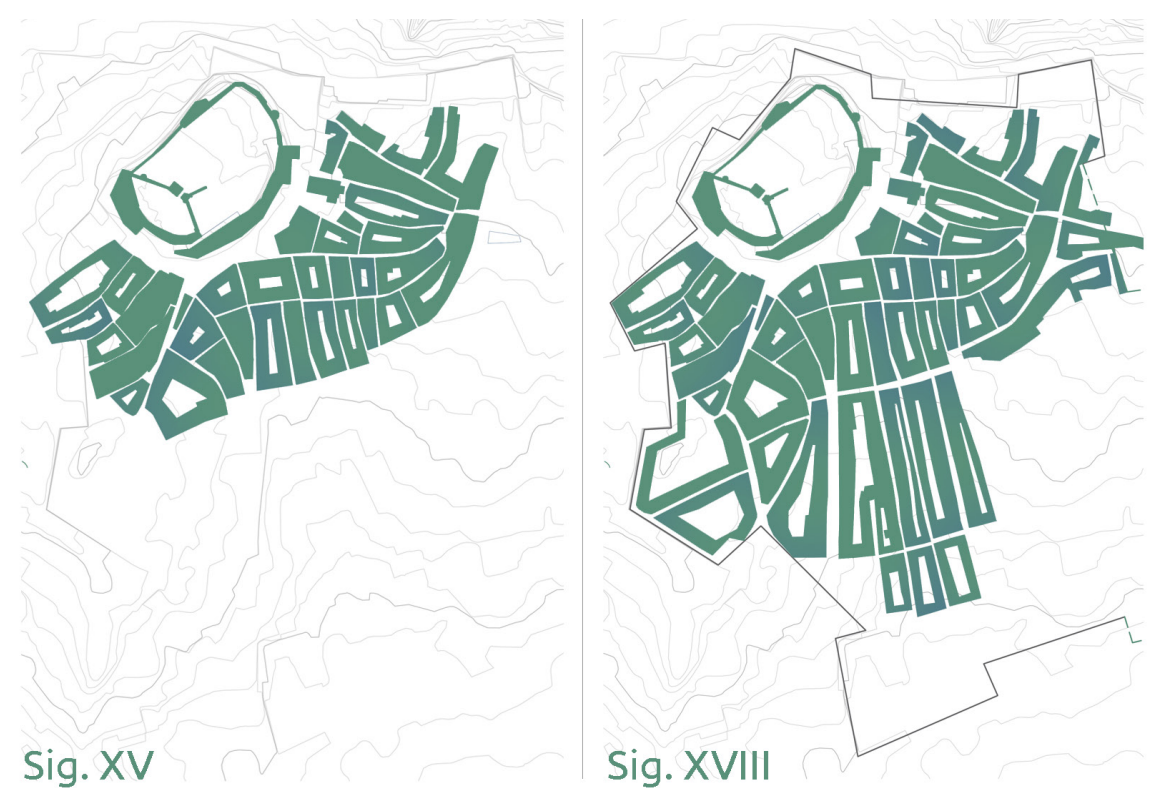

Sig. XVIII

Esta parcela estrecha y larga no tiene relación con la casa mediterránea de patio central. Denota la importación de un modelo urbano y de hábitat septentrional, bastante generalizado, implementado en el sur de la península tras la conquista cristiana y que sustituye a la anterior matriz urbana afiliada al mundo mediterráneo. Esta parcela, ampliamente difundida en el Portugal medieval, es frecuentemente nombrada como "lote godo" (Trindade 2009, 41). Será la base del planeamiento urbano medieval portugués. En Moura, el planeamiento del siglo XIV basado en ejes lineales predominantes de los dos primeros arrabales evolucionaría a un planeamiento cuadricular de calle larga con transversales en la zona construida durante el siglo XV para unir los dos arrabales hasta entonces aislados. Esta zona se denominaría el arrabalde novo, arrabal nuevo, y se mantiene aquí el uso de la parcela estrecha y profunda. Se percibe un cambio de orientación en las manzanas, ahora dispuestas de forma perpendicular a la vía longitudinal. Posteriormente, a largo de los siglos XVI y XVII, la expansión de la trama urbana se hará en dirección al sur, prolongando las líneas de las calles transversales (Trindade 2009, 208). Esta continuidad de las líneas de expansión aportará unidad morfológica al conjunto urbano, aunque en la expansión hacia el sur, el catastro se compone de parcelas doblemente mayores a las planeadas hasta entonces (Duarte y Lamas 1988, 42).

En 1658, durante la Guerra de la Restauración, una nueva muralla es erigida (Macias y Gaspar 2005, 15) alrededor de toda la vila existente hasta la fecha y dejando incluso bastantes espacios vacíos dentro de su perímetro. La ocupación de estos espacios se hará lentamente, a lo largo del siglo XVIII, manteniéndose grandes áreas vacías hasta el siglo XIX, e incluso el XX. Esto se 
traducirá en un desarrollo con baja presión demográfica/constructiva, que resultará en casas mayoritariamente térreas, propiedades con áreas elevadas y jardines amplios dentro del perímetro de murallas.

\section{TIPOLOGÍAS HABITACIONALES-EXPERIENCIAS}

\section{Zona 1-Moraría}

Esa parcela "goda" aludida por Trindade sería la unidad base de la delineación del barrio de la mouraria. El diseño de las calles sigue el declive del terreno, aunque manteniendo formas rectilíneas paralelas, denotando el planeamiento de la barriada. Las manzanas se conforman mediante la agrupación de dos hileras de parcelas adosadas, dispuestas simétricamente con eje longitudinal. Las calles miden de ancho aproximadamente $3 \mathrm{~m}$, llegando a 2,50 m en las partes más estrechas. Las parcelas, después de pasados ocho siglos sobre su delimitación original, presentan hoy una profundidad media entre 13 y $15 \mathrm{~m}$, con una anchura media de 5-6 $\mathrm{m}$ y una amplitud entre 3 (valor mínimo registrado) y $10 \mathrm{~m}$ (valor máximo registrado). Las parcelas no están, en la mayoría de los casos, ocupadas en su totalidad, ya que el área posterior funciona como patio. Comparándola con otras latitudes del Alentejo, se observa bastante regularidad respecto a las dimensiones medias de esta parcela, encontrándose rectángulos de 5 a $7 \mathrm{~m}$ por 10 a $13 \mathrm{~m}$ en Castelo de Vide (Bicho 1999, 103) y medidas entre 7 y $8 \mathrm{~m}$ de ancho por 11 a $14 \mathrm{~m}$ de profundidad en Estremoz (Rosado, Liberato, y Costa 2018, 294).

Predominan las casas de una planta, aunque en la parte norte del barrio sean visibles aumentos de piso recientes (siglo XX). Muy marcadas en las fachadas de las calles están las grandes chimeneas paralelepipédicas, llamadas de escuta por los locales, ya que a través de estas se escuchan, dentro de casa, las conversaciones de la calle. Se contabilizan en la Moraría diecinueve chimeneas de escuta, otras seis de sección rectangular pero no ubicadas en el plano de la fachada y tres de sección circular. La ocupación de parte de la fachada con el volumen de la chimenea resulta en planos con pocas aberturas: muchas veces el único hueco en fachada es la puerta de entrada.

Las paredes son de mampostería o de tapiales, manteniendo una espesura constante de $60 \mathrm{~cm}$. Aseguran el soporte estructural de los tejados y, cuando existen, de los pisos en soberado (altillo en el desván del tejado de dos aguas). Las estructuras de cobertura se basan en vigas de madera con recubrimiento de baldosas cerámicas o cañizo bajo hileras de tejas árabes, generalmente a dos aguas con cumbrera paralela a la fachada principal. Los compartimentos se encuentran adyacentes, frecuentemente dispuestos en línea, en número de dos a cuatro, con gran versatilidad funcional. 


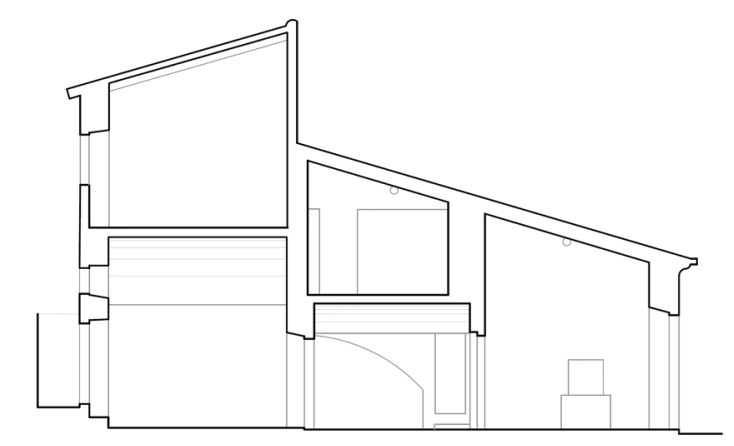

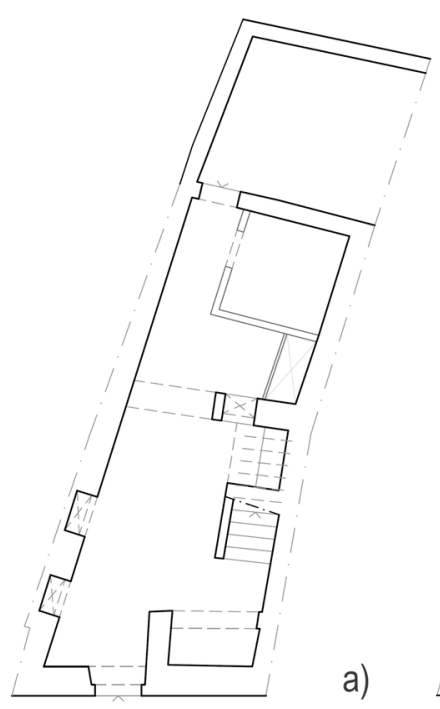

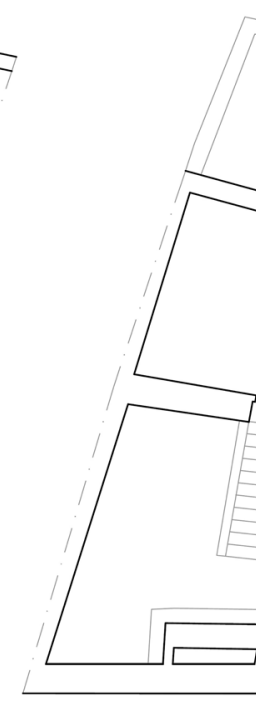

$1 \mathrm{~m}$
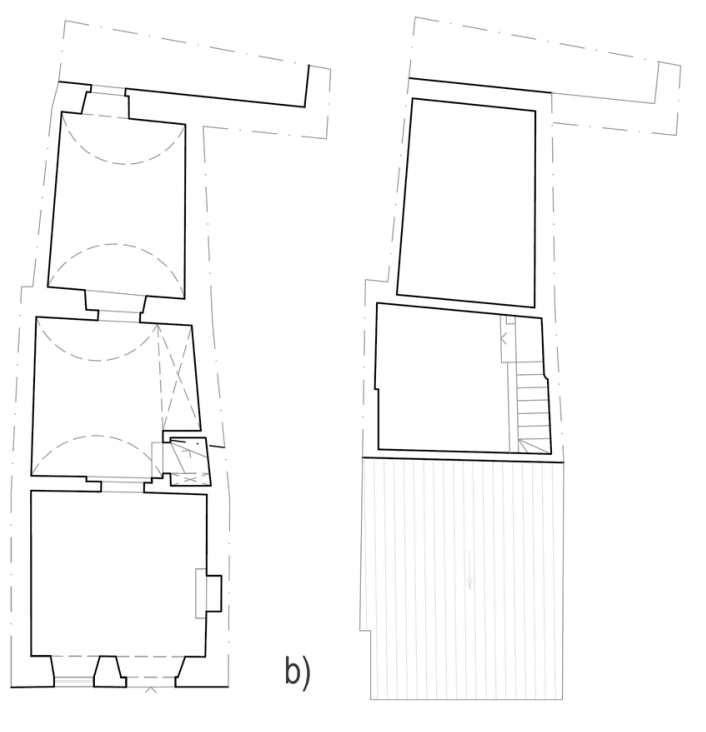

Casas de divisiones alineadas con sobrado (tipo

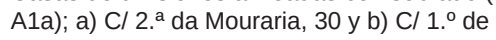
Dezembro, 24 | plano Ana Rosado

\section{Zona 2-Carretera de Aroche}

Teniendo como base la misma parcela estrecha y profunda se construyó el arrabal de la carretera de Aroche. Sus principales manzanas, ancladas al secular camino, tienen un trazado marcadamente lineal pero con geometría irregular. Las principales calles, Rua de Aroche y Rua do Espírito Santo, miden entre 4 a $5 \mathrm{~m}$ de anchura, y la Rua da Capinha Rota llega a un valor mínimo de $3,50 \mathrm{~m}$. Las parcelas muestran cierta regularidad de ancho medio, con 5,50 m en esta zona, aunque también existen parcelas muy estrechas, de $2,75 \mathrm{~m}$. La profundidad media repite los $15 \mathrm{~m}$ encontrados con frecuencia en la Moraría. Tanto en este arrabal como en el de la Moraría, en las parcelas ocupadas por viviendas más antiguas, la construcción tiene una profundidad alrededor de $9 \mathrm{~m}$, dejándose libre el fondo de la parcela. Esto parece indicar una tendencia constructiva, una dimensión de profundidad de casa independiente del tamaño de la parcela, que desapa- 
rece ya durante el último siglo cuando las casas crecen en superficie y ocupan el patio trasero.

En la Rua de Aroche y sus paralelas, las casas son en la gran mayoría de los casos de dos pisos, aunque muchas de las adiciones hayan sido construidas en el siglo XX. En la transversal Rua da Romeira, probablemente por su condición periférica, se encuentran varios edificios muy poco alterados -uno de ellos actualmente adjudicado al Museu Municipal- con trazos muy sencillos: fachada revestida a cal blanca, aberturas pequeñas y sin marco de cantería, aleros simples de teja saliente. Puntualmente aparecen puertas y ventanas enmarcadas por piedra trabajada al estilo gótico (Rua do Espírito Santo) y renacentista, con linteles rectos entablados con cornisa. Se mantiene, tal como en la Morería, la predominancia de la tradicional chimenea de escuta, con diecisiete ejemplares, contra seis de sección rectangular y once de sección circular. Las chimeneas de escuta tienen mayor incidencia al norte de la Rua de Aroche, en la zona más periférica y menos adulterada. Las chimeneas de sección circular se encuentran sobre todo en la parte sur de esta zona, junto al Arrabal Nuevo.

A nivel interior, se siguen utilizando soberados, pero aquí con una particularidad que no se encontró en la Morería: soberados sobre estructuras de bóvedas de ladrillo.

\section{Zona 3-Arrabal Nuevo}

Lo que en la zona de la carretera de Aroche aparecía como excepción, en el Arrabal Nuevo será una regla: los pisos bajos de los edificios son, en su gran mayoría, cubiertos por bóvedas de ladrillo, de distintos formatos. No es ajeno a este dato constructivo el hecho de que aquí esté ubicado el corazón comercial de Moura y los bajos sean ocupados de forma muy extensiva por locales de comercio y gastronomía. Aparece también aquí un tipo de vivienda sin presencia en las dos zonas más antiguas: la casa noble, de dos o más pisos, con el primer piso marcado en la fachada con ventanas de balcón.

El Arrabal Nuevo, una implantación del siglo XV con manzanas cuadrangulares, mantiene formas orgánicas de transición entre el anterior arrabal de la carretera de Aroche, a levante, y el diseño rectilíneo de las nuevas calles perpendiculares. El planeamiento en cuadrícula no significa necesariamente uniformidad de parcelario, ya que dentro del diseño perpendicular se construye una jerarquización en tamaño de las manzanas. Se da una zonificación a pequeña escala: en las manzanas más estrechas se concentra la vivienda corriente, y en las manzanas más anchas, que permiten vacíos en su interior, se ubican las casas acaudaladas o eruditas y los comercios en los pisos bajos. 
Dos bajos en la calle $1 .^{\circ}$ de Dezembro. Bóvedas de distintos formatos | plano Ana Rosado

La zona está estructurada por una calle longitudinal en sentido este-oeste, Rua dos Ourives/Martinho Ganhão, pero que no funciona como calle principal. Los frentes principales de las parcelas se abren para las calles transversales. La profundidad media de las parcelas es, en las manzanas anchas, de 17 $\mathrm{m}$, y en las manzanas estrechas y parcelas orientadas a la calle dos Ourives/ Martinho Ganhão, de aproximadamente $12 \mathrm{~m}$. Estos valores indicativos son difíciles de asegurar para una dimensión mediana de anchura de parcela; la zona, debido a su atractivo de centralidad, ha sufrido más cambios y reconstrucciones en el edificado que ninguna otra, materializados muchas veces en la aglutinación de parcelas para generar edificios de grandes dimensiones.

Las casas de un único piso son aquí la excepción, y casi siempre son viviendas corrientes. Coincidiendo con la generalización de los edificios de dos plantas, las bóvedas como soporte del piso elevado dejan de ser puntuales para pasar a ser la regla, incluso en las casas corrientes como puede verse en la $\mathrm{C} / 1 .^{\circ}$ de Dezembro, n. 24 (modelo b del plano de la p. 64) donde los dos soberados están sobre dos bóvedas de cañón. Las mencionadas bóvedas se encuentran en diferentes formatos y dimensiones - de cañón, de aristas, abobadilhas (bóvedas tabicadas)-, muchas veces coexistiendo en el mismo edificio. Se adecuan a la espacialidad de las divisiones: son más frecuentes las bóvedas de cañón en compartimentos de mayor profundidad, como pasillos, las bóvedas esquifadas y las bóvedas tabicadas, estucadas con motivos decorativos, en los salones delanteros. Igualmente, la presencia de las chimeneas de escuta baja considerablemente: la ocupación de parte de la fachada con un elemento de bloqueo es poco compatible con el carácter comercial de la zona, que requiere frentes abiertos y permeables. La chimenea se recoloca en los compartimientos posteriores del edificio.
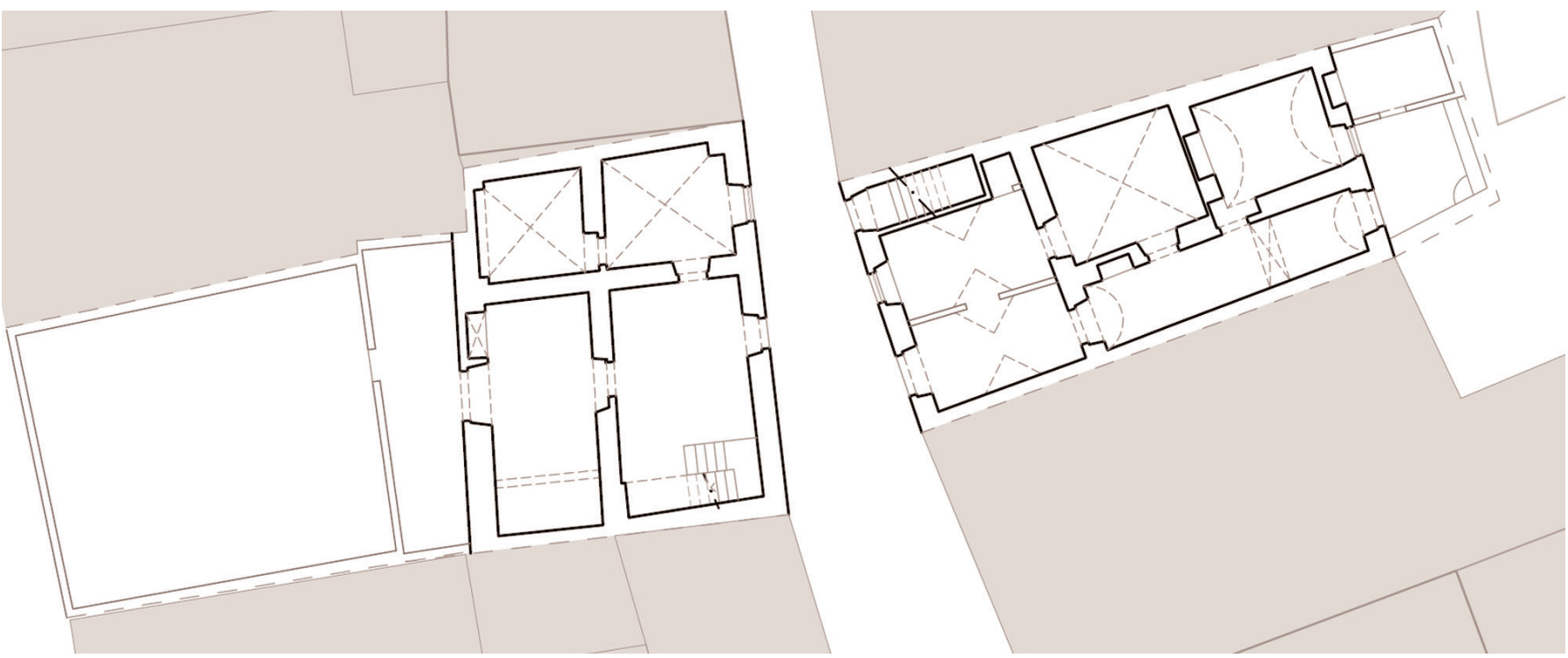
a)

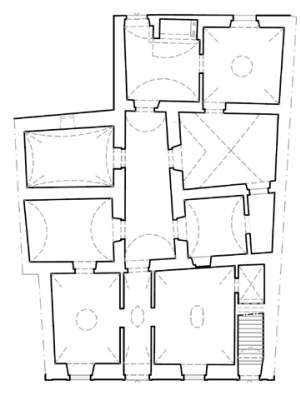

Rua de S. Pedro 50 b)

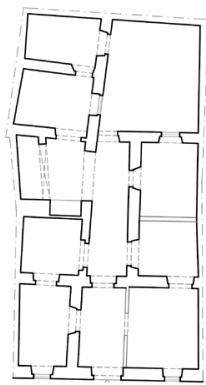

Rua da Oliveira 21-21A c)

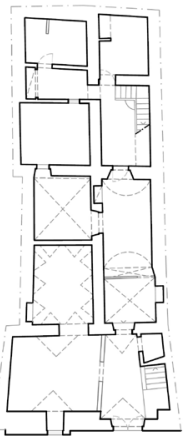

Rua da Oliveira 4 d)

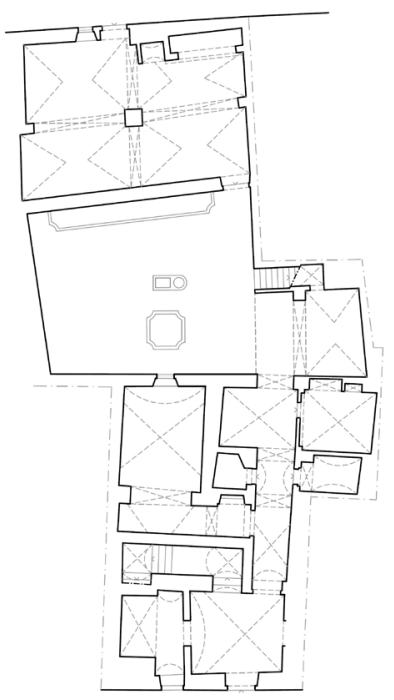

Rua Cons. Aug. Castro 24

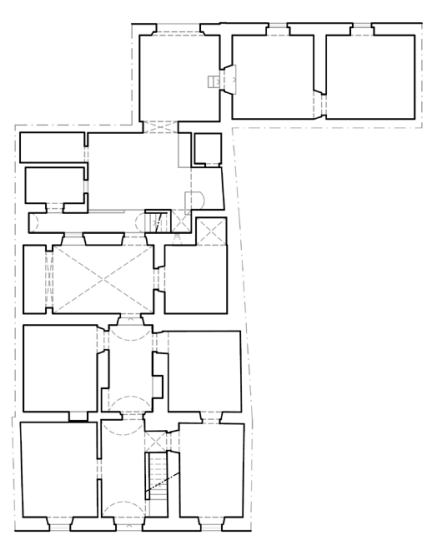

Rua de S. Pedro 19

Tipológicamente, es la aparición de la casa erudita la que marca la diferencia Varios ejemplos de tipo C2a, C2b y C3. Pasillos y proto-pasillos en posición lateral y central | plano Ana Rosado para las zonas anteriores. En estas, gana protagonismo la escalera, como elemento de representación, cambiando su posición adosada a la medianera de la casa -posición casi generalizada en la casa corriente- a ubicarse transversalmente entre la primera y segunda crujía de la casa. Van apareciendo, con el crecimiento en tamaño y complejidad de las casas, elementos de distribución espacial, precursores del pasillo. 


\section{Zona 4-Expansión moderna}

En la zona de expansión al sur de la calle de la República, planeada durante los siglos XVI-XVII y consolidada hasta el siglo XIX, el diseño urbano es realizado en base a un sistema jerarquizado de calles principales y calles de servicio. Se rompe con la tradición medieval de crear manzanas de dos hileras simétricas de parcelas adosadas, sistema mayoritariamente empleado en Moura hasta entonces. Al utilizarse un sistema de calles principal/servicio, las manzanas se dividen en parcelas adosadas que ocupan todo el ancho de la manzana y, así pues, tienen marcada la jerarquía de accesos frente-trasera, siendo la entrada por la calle principal destinada a la familia y visitas, y la trasera a vehículos, caballeriza y servicio doméstico. Las calles principales son la de Serpa Pinto, de S. Pedro y 5 de Outubro.

En su estado original, las manzanas se configuraban de la siguiente manera: entre la calle Serpa Pinto (aproximadamente $14 \mathrm{~m}$ de ancho) y la calle de S. Pedro (entre 4 a $6 \mathrm{~m}$ de ancho) solo hay servicio en la parte sur de la manzana, a través de un callejón. Entre la calle S. Pedro y la calle da Parreira (servicio -aproximadamente $4 \mathrm{~m}$ ancho-) las parcelas tienen $15 \mathrm{~m}$ dedicados a la construcción de la casa, seguidos por $5 \mathrm{~m}$ de patio exterior y $5 \mathrm{~m}$ de caballerizas, con acceso por la calle de servicio. El mismo modelo de implantación se encuentra en el lado de levante de la calle 5 de Outubro (entre 5 a $8 \mathrm{~m}$ de ancho) con servicio para la calle dos Espingardeiros. La manzana en el lado poniente de la calle 5 de Outubro (serventía para la calle da Parreira) parece haber tenido también una configuración original de casa + patio + caballeriza, pero con dimensiones superiores: aproximadamente $20+6,5+$ $8,5 \mathrm{~m}$ respectivamente. No obstante, la gran profundidad de parcela resultante, en torno a $35 \mathrm{~m}$, parece haber proporcionado la división en dos subparcelas de unos $18 \mathrm{~m}$, y consecuentemente la jerarquía frente/trasera es menos visible aquí que en las manzanas del entorno. Esta organización del parcelario indica una respuesta tipológica a la falta de un tipo de vivienda acaudalada en el área medieval, que incluye varias funciones más allá del cobijo del núcleo familiar: zonas de servicio, dormitorios de personal, caballerizas, etc. (ejemplos d y e de la página 67). En las zonas más antiguas, se intentó remediar este déficit con la aglomeración de múltiples parcelas, pero las casas con mayores dimensiones seguían casi siempre teniendo la misma relación con el espacio público que las casas corrientes. Una excepción de casa con caballeriza con acceso por las zonas traseras en el Arrabal Nuevo se ve en la calle Conselheiro de Castro, 24 (ejemplo d de la página 67).

Al sur de la calle del Escalatrim, las tres manzanas mantienen la anchura de las situadas inmediatamente a norte, con las calles norte-sur siguiendo su carácter de directrices de cuadrícula urbana. Ya la lógica de organización interna en estas manzanas vuelve a ser la de parcelas resultantes de su división simétrica, creando una zona de vivienda popular. La baja presión 
constructiva, ya anteriormente mencionada, lleva a que esta zona de expansión al sur se componga de parcelas extensas, con amplios espacios vacíos hacia donde las casas se expandirán durante los siglos XVIII y XIX. Un ejemplo de adición a posteriori es visible en la calle de S. Pedro, 50 (ejemplo a de la página 67), donde se ha restructurado una casa, o por crecimiento hacia el patio trasero, o por aglutinación de dos parcelas, desplazando la cocina a la última crujía e incorporando un compartimiento central de distribución del espacio. Este elemento, similar a un pasillo largo, se va repitiendo en un amplio número de casas de la zona, indicando la consolidación del cambio tipológico habitacional del sistema de compartimientos adyacentes a la generalización del pasillo y distribución de circulación.

\section{Materiales}

En todas las zonas analizadas del centro histórico de Moura, independientemente de la dimensión o tipo de casa, se repiten una serie de materialidades y procesos constructivos. De los materiales, es el barro el protagonista de la construcción doméstica. El uso del barro ya era generalizado en el Alentejo, desde, por lo menos, el siglo XV, de cuando nos llegan registros históricos de pavimentos ladrillados en la vecina ciudad de Évora (Conde 2011, 125), aunque lo más probable es que el uso de cerámicos se mantenga constante en las técnicas constructivas del Portugal meridional desde el período romano (Ribeiro 1961, 38). El barro se utiliza en la forma de ladrillo común de construcción, baldosas de suelo y tejas de cobertura. Son muy frecuentes en el Alentejo, sobre todo en latitudes más septentrionales, las estructuras de piso de viguería de madera, con pares y contrapares, recubiertos por ladrillo plano, una solución también común en Andalucía. En Moura, esta es
Materiales de construcción: a) adobe, b) tapiales y cañizo, c) paredes revestidas a cal | fotos Ana Rosado
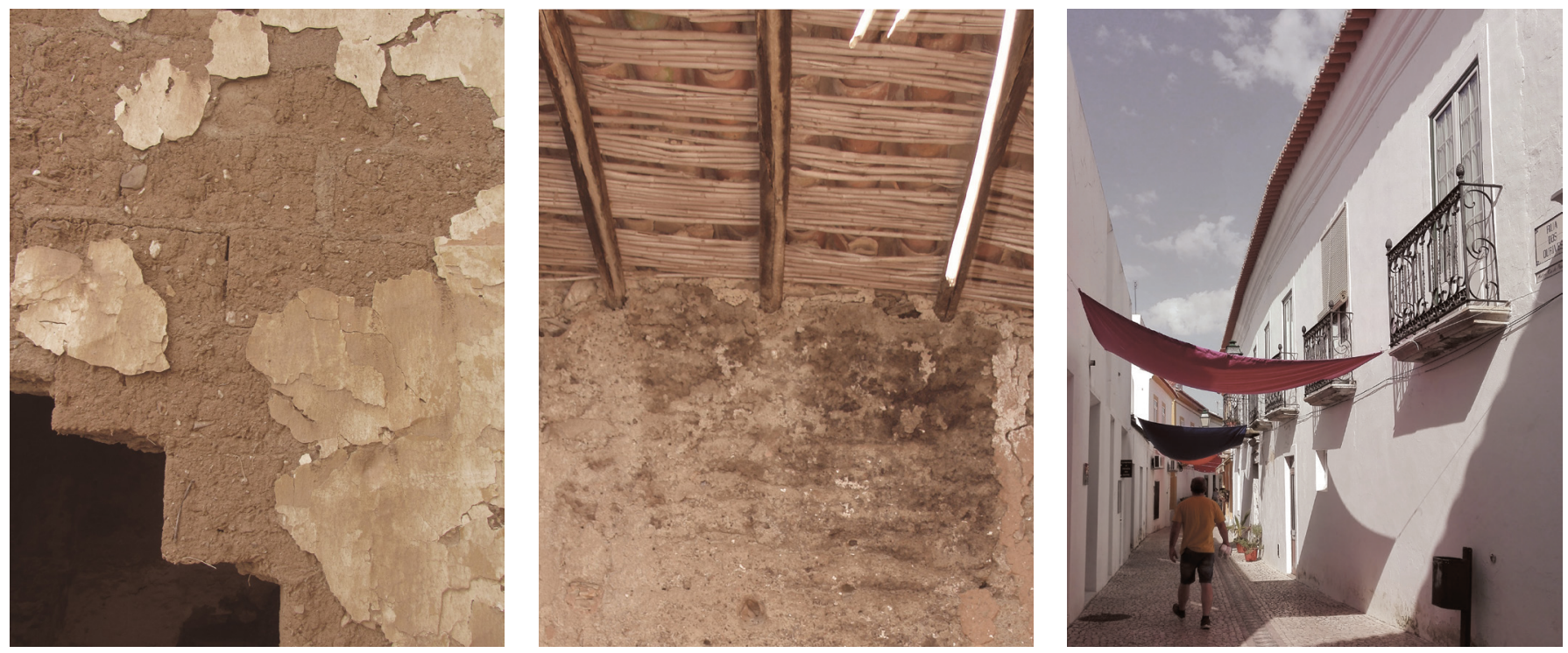

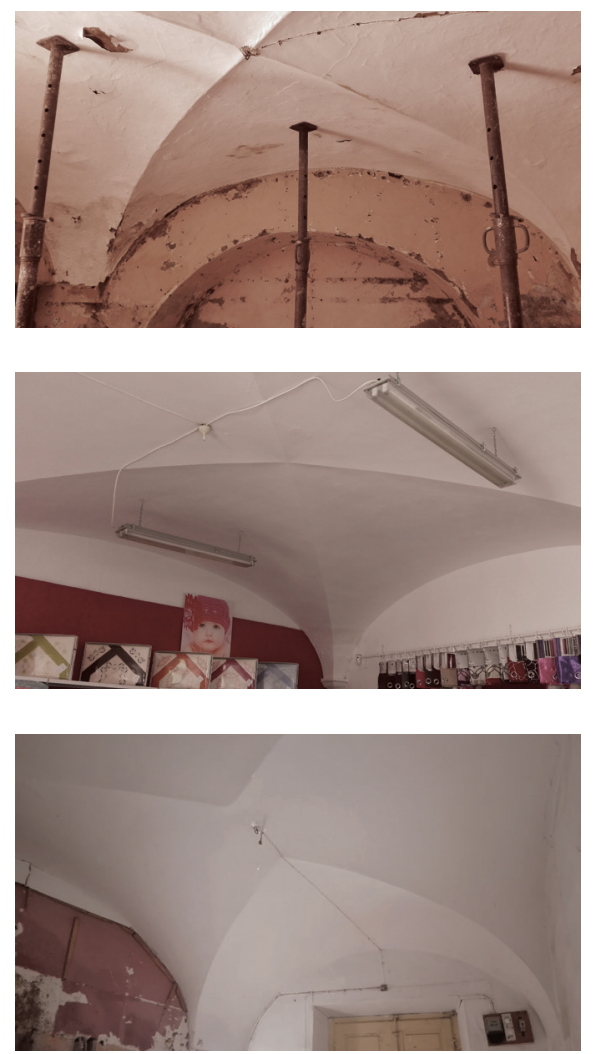

Bóvedas: a) y b) de arista rebajada, c) de lunetas rebajada | fotos Ana Rosado la solución de estructura de piso más encontrada en las zonas urbanas primitivas, la Mouraria y la carretera de Aroche. La misma solución constructiva es encontrada para tejados, con los forjados leñosos cubiertos de teja y, a veces, con una hilera intermedia de ladrillo plano. También se encuentra una variante con cañizo en lugar del ladrillo. No obstante, en general, las soluciones vegetales son poco frecuentes; incluso el uso de madera es mayoritariamente estructural y, en Moura, postergado a favor de las soluciones de soporte en ladrillo. El ladrillo también aparece como elemento generador de paredes, en combinación con piedra de mampostería y asignado a la delimitación de puertas y ventanas. Asimismo, se utilizan en las paredes tapiales de tierra cruda y, en tabiques delgados, ladrillos de adobe. Los paramentos, tanto interiores como exteriores, son invariablemente revestidos a cal blanca, siendo muy excepcional el uso de colores.

En general, estas técnicas constructivas son transversales en todo el Alentejo. Hay una, sin embargo, muy distintiva de la ciudad: el uso generalizado de ladrillo en estructuras de soporte de piso: bóvedas y abobadilhas (bóvedas tabicadas). Estas cubiertas arqueadas se distinguen de las bóvedas tradicionales por el uso del ladrillo de panderete a lo bajo, o sea, usando el lado mayor siguiendo la superficie del arco bóveda, y la altura del ladrillo será el espesor de la bóveda tabicada (Santos 2014, 27). Esta solución es la más económica de las dos al necesitar menor cantidad de material y tener mayor rapidez de ejecución, ya que el peso total -y consecuentemente las cargas estructurales- son menores que en la bóveda tradicional. La técnica de la bóveda tabicada es común en la región del Alentejo, pero es especialmente utilizada en el margen izquierdo del Guadiana. Se teoriza que es a partir de aquí que la técnica se difunde por la vecina Extremadura alrededor del siglo XIX, tornándose su uso muy frecuente en la Baja Extremadura (Carmona Barrero 2011, 51).

Encontramos, en las zonas analizadas de la ciudad con mayor dinamismo comercial y económico, una gran variedad de tipo de bóvedas y abobadillas en casi todos los tipos de casa registrados. Entre las bóvedas corrientes, son mayoritarias las de arista, en muchos casos rebajadas, y las de cañón. Por su configuración geométrica, cada clase se conecta directamente a un tipo de división de la casa: las bóvedas de arista recubren estancias con formas similares al cuadrado con una media de $4 \mathrm{~m}$ de lado, nunca superando los 5 $\mathrm{m}$, sean casas delanteras o cuartos interiores (tipo a en esta página). Las de cañón se asocian a divisiones prolongadas, de anchura entre los 4,00 y los 9,50 m, y profundidad de 16,5 a 20,0 m, como pasillos. Las bóvedas tabicadas tienen mayor flexibilidad de formas; de estas, una de las más comunes es la bóveda esquifada, en la que las aristas que nacen en cada canto se unen en una superficie aplanada. Se utiliza en compartimientos cuadriláteros con más o menos irregularidad de ángulos, y situados en una posición indiscriminada en la casa. Igualmente se encuentra bien distribuida por la casa 


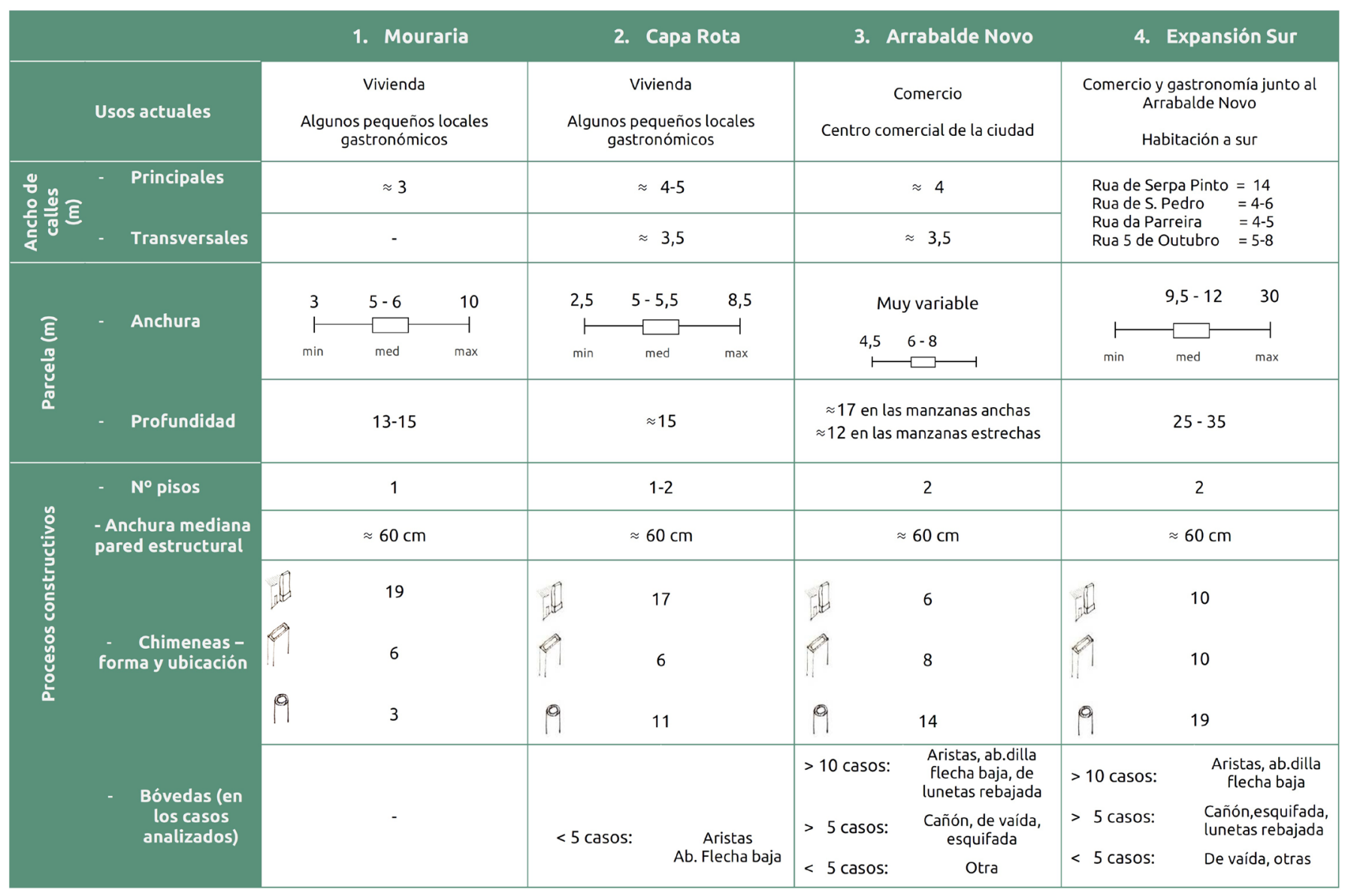

Métricas urbanas y constructivas por cada zona del centro histórico | tabla Ana Costa Rosado, María

la bóveda tabicada de cañón de flecha muy baja, frecuentemente inferior a Teresa Pérez Cano, Miguel Reimão Costa mitad de la dimensión del arco. Otros tipos más complejos, como la bóveda de lunetas rebajada ${ }^{2}$ (tipo c en la imagen de la página anterior) y la vaída, son casi siempre usados en los compartimentos delanteros, como en la casa de entrada o en salones de visitas, vinculados a la zona noble y social de la casa. Estos se encuentran frecuentemente decoradas con estucados con motivos vegetales o geométricos.

\section{RESULTADOS Y DISCUSIÓN}

A través del análisis de 143 casos de estudio del centro histórico, cuyas características formales y materiales han sido descritas en el apartado anterior, se han podido definir tres grandes familias de tipos de casas, y 12 variantes de tipos habitacionales en Moura. Los resultados obtenidos en esta investigación derivan del análisis de datos obtenidos en levantamientos in loco y consultas de archivo realizadas entre 2017 y 2018 en Moura. Del 
a)

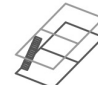

b)<smiles>[CH]</smiles>

1.

c)
A. []

2.

用

$1 . \Perp$

B.

$\square$

c.

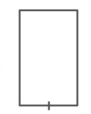

2.

Cuadro de tipos de vivienda tradicional en Moura

I planos Ana Costa Rosado, María Teresa Pérez

Cano, Miguel Reimão Costa
边自日

再

䕗自

ํㅐ는

舫
1.

2. 田

1

a)

$\varnothing$

四

b)

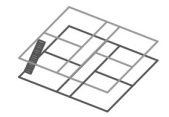

A-

国

a)

a)

$\varnothing$

Fin

b)

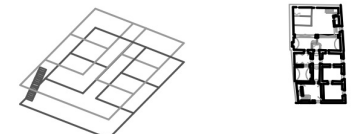

3.

a)

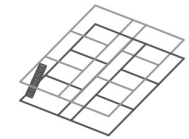

相 
proceso de análisis resultó la agrupación y clasificación de los tipos habitacionales por categoría, con base a los parámetros de (1) forma de parcela, (2) compartimentación interior y (3) existencia/posición de escalera, como muestra la tabla de la página anterior.

En base al primer criterio, la forma de la parcela, se dividen los casos en tres categorías: la categoría A engloba los casos asociados a la parcela "goda", estrecha y profunda; la categoría B corresponde a la parcela de frente largo pero de corta profundidad, y la $\mathrm{C}$ a la parcela rectangular de fachada larga y fondo profundo. La categoría A tiene un número mayor de casos y variaciones de tipo que las demás, ya que la parcela estrecha y profunda fue la base de urbanización de las zonas de génesis medieval, usándose allí sistemáticamente. Dentro de cada categoría, los casos se agrupan de acuerdo con su organización espacial interna, es decir, en base a la distribución de las estancias en planta. En la categoría A, la lógica de distribución interna puede
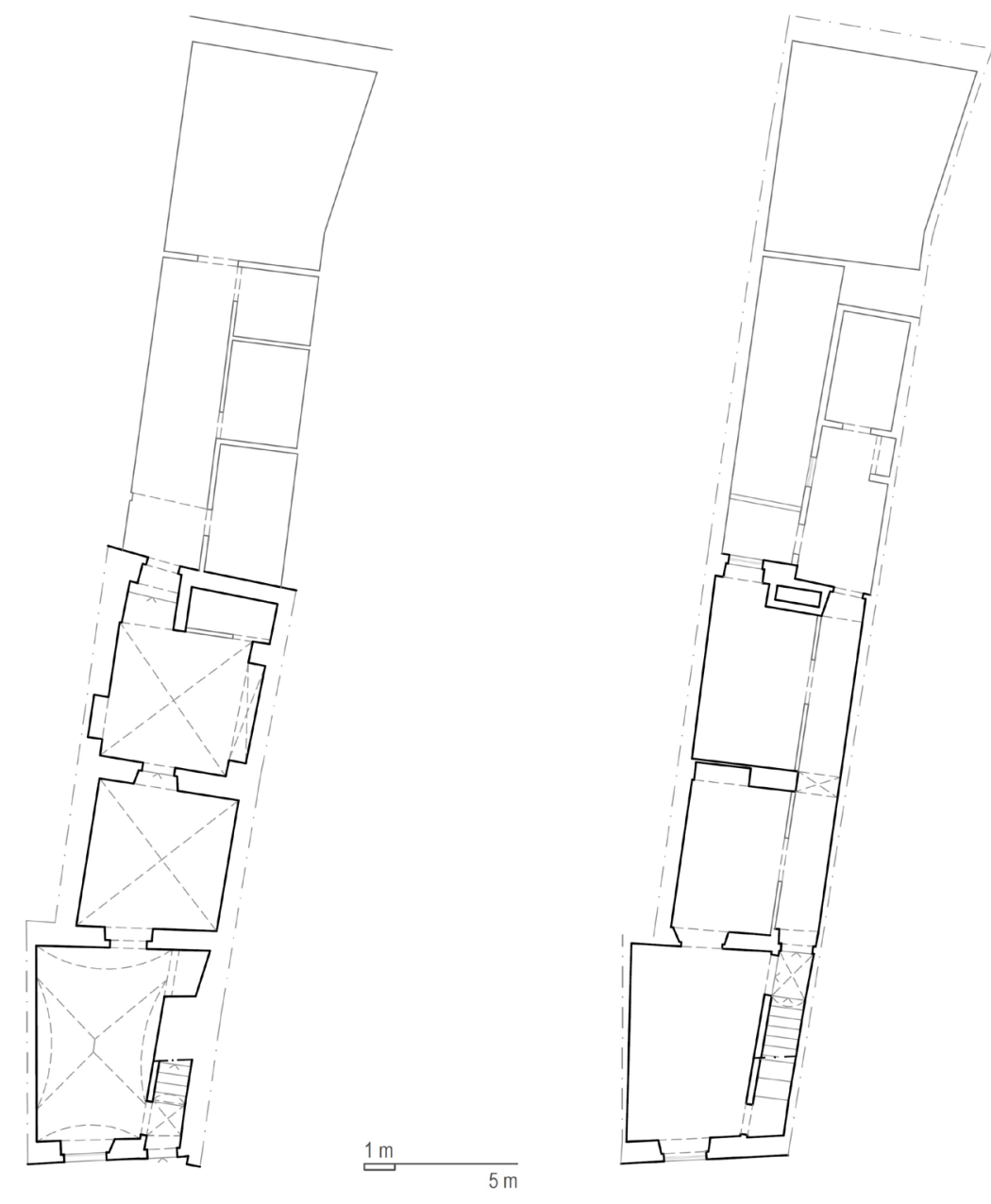


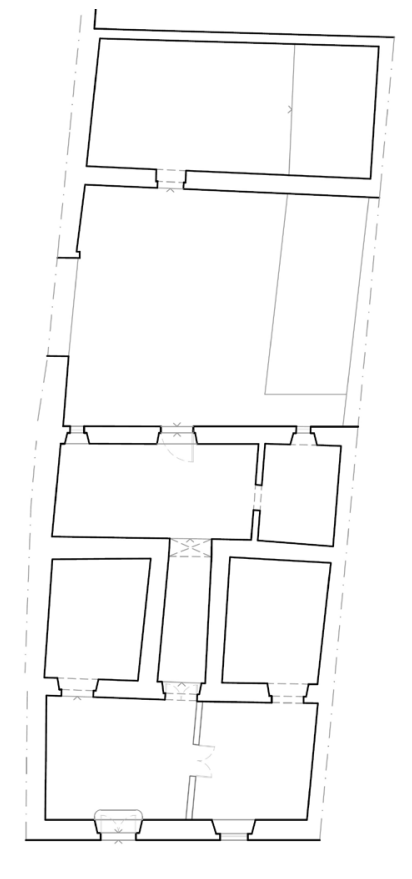

Rua S. João de Deus 10

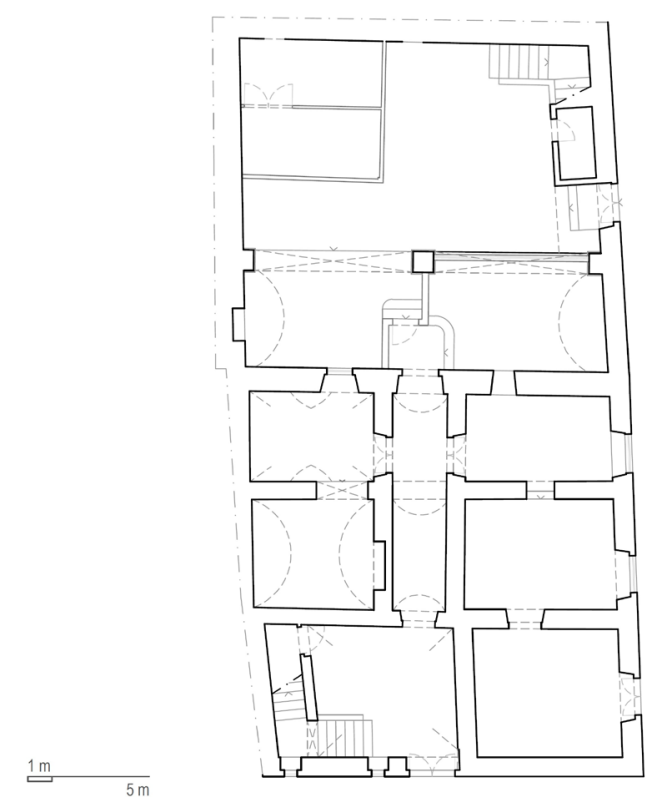

Rua da Oliveira 2 a) Tipo C2a (C/ S. João de Deus 10) y b) Tipo C2b (C/ da Oliveira 2) | planos Ana Rosado ser (1) lineal, con las divisiones dispuestas continuamente en profundidad, una tras otra; o (2) bi-lineal, en que la casa resulta de la aglutinación de dos parcelas de distribución lineal. Dentro de cada grupo, existen variaciones en relación con el número de pisos (con o sin piso elevado) y a la posición de la escalera. A estas variaciones es atribuida una letra minúscula $(a, b, \ldots)$ y la conjunción de la identificación de categoría, grupo y variante nos dan la nomenclatura del tipo. Por ejemplo, la casa ubicada en una parcela estrecha, con tres o más estancias alineadas y con la escalera en posición lateral apoyada en la medianera será el tipo A1c.

En las categorías B y C, ambas con parcelas de frente ancho -las parcelas de la categoría $B$ de profundidad corta-, la planta muestra casi siempre más que una división por crujía, una distribución que potencia la introducción del pasillo. La categoría C se divide en tres grupos, de acuerdo con la existencia y posición de este elemento de circulación: el grupo 1 congrega los casos sin pasillo, en que una única zona de entrada es seguida de dos compartimentos paralelos; en el grupo 2, desde el compartimiento de entrada se accede también a una o dos cámaras, pero sobre todo, al pasillo que lleva directamente a la última crujía donde se ubica la cocina. En el grupo 3, la estancia de entrada es sustituida por un pasillo con acceso directo desde la puerta principal, y que continúa en profundidad hasta la cocina. 
La caracterización tipológica presentada es válida para esta área concreta y es resultado del muestreo obtenido. No es imposible que, con un aumento de casos de estudio, otros tipos de casa pudiesen haber surgido, aunque, se considera que esos serían casos excepcionales y que los tipos fundamentales de la vivienda de Moura están representados en la tabla 2. Esta convicción emana de la correspondencia encontrada entre estos tipos y otros similares obtenidos para distintos puntos del Alentejo, bien dentro del ámbito de esta investigación o las realizadas por otros autores. En Moura hay una incidencia mayor de tipos de frente largo (más de la mitad de los analizados) que en otras ciudades alentejanas situadas al norte (véase Rosado 2019, $110)$, y se dividen en muchas más variaciones que los tipos de frente estrecho. Estos tipos están directamente relacionados con la parcela estrecha goda que en Moura está presente sobre todo en los dos primeros ensanches extramuros -Moraría y calle de Aroche-, y que cae en desuso con el final de la Edad Media, a favor de parcelarios de mayores dimensiones. Los tipos de frente estrecho, definidos en la categoría A, quizás por este carácter generalizado de la parcela goda con la que están relacionados, tienen muchos paralelismos con tipos encontrados en otras latitudes. El tipo Ala se corresponde con una casa de dos células muy común no sólo en Alentejo, sino en todo el territorio portugués, que representa la unidad básica de vivienda: un espacio de vivencia familiar, que alberga las actividades cotidianas como el fuego y la preparación de alimentos, y un espacio interior asociado al almacenaje de víveres y al reposo. En Moura, este tipo se consolida con la introducción casi generalizada de un soberado sobre el segundo compartimento, y muy frecuentemente se encuentra con una prominente chimenea de escuta en la fachada principal.

Los casos de categoría A, de distribución lineal de estancias, son los únicos en los que se ha podido encontrar paralelismos con tipos al otro lado de la frontera, en la Sierra de Aracena. Cascales Barrio identifica en Alájar un tipo denominado "casa de jornalero", asociado a una vivienda corriente con fachada estrecha, dos o tres divisiones alineadas en profundidad, cubiertas por doblao -soberado- que, sin ser un piso completo, con el tiempo gana protagonismo y una pequeña portada con balcón en la fachada principal (Cascales Barrio 2017, 280). En estos casos, la escalera de acceso al soberado se encuentra casi siempre paralela a la fachada principal, asociándose a los ejemplos de Alájar con el tipo A1d de Moura, aunque con cambios importantes en la posición y tipo de chimenea. De forma genérica, se identifica para la vivienda de la Sierra de Aracena una versatilidad de los espacios de la casa de jornalero (aunque en otros tipos de casa las divisiones estén bien delimitadas) como previamente se ha mencionado para el caso de Moura. La definición de funciones de los compartimientos se intensifica con el paso del tiempo y, sobre todo, con el aumento del poder económico de los ocupantes de la casa (Cascales Barrio 2017, 217) es decir, con el crecimiento de la casa en superficie y complejidad. 
En Moura, este proceso es muy visible, ya que los cambios en la casa acompañan directamente al crecimiento urbano. Si la categoría A está muy vinculada a los dos arrabales primitivos, los casos $B$ y $C$ se van a desarrollar sobre todo en las zonas de expansión de los siglos XVI y XVII en manzanas de dimensiones superiores. El soberado se transmuta en un segundo piso bien definido, pudiendo llegar la casa a dividirse en dos plantas independientes. Es en los tipos B y C donde se ve la introducción de espacios de circulación: proto-pasillos primero -espacios con la única función de distribución espacial, pero de anchura considerable, con dimensiones no muy distintas a las demás divisiones- y pasillos estrechos con profundidad superior a una crujía. Estos espacios de circulación surgen tanto adosados a una medianera, dando acceso a una hilera de estancias laterales; o en posición central en la casa, sobre el eje central de la vivienda (plano de la página 67). Parece ser que el espacio de circulación fue inicialmente relegado a la segunda crujía, ya que ahí aparece definido por paredes estructurales. Esto significa que, en un primer momento, los tipos C3 serían C2 y la extensión del pasillo hasta la zona de entrada ocurre ya probablemente en el siglo XIX, asociado a un importante cambio constructivo: la introducción de muros no portantes, los tabiques. Estos elementos leves sirven para compartimentar divisiones mayores, creando una especialización de los espacios muy asociada a los cambios familiares y de acuerdo a la idea de la vivienda del periodo decimonónico. Se ve que la delimitación del pasillo en la entrada de la casa va acompañada de campañas decorativas, con la introducción de bóvedas tabicadas de acuerdo con la dimensión de los nuevos espacios (véase $\mathrm{C} /$ de $\mathrm{S}$. Pedro 50, ejemplo a del plano de la página 67).

Hoy, es la introducción del hormigón armado como sustituto de las estructuras de piso -tanto leñosas como abovedadas- la que representa la mayor transformación y, simultáneamente, el mayor riesgo para la conservación patrimonial de la casa tradicional en el Guadiana portugués. De las señaladas amenazas surge la mayor motivación para el desarrollo de la investigación científica sobre la arquitectura tradicional: si las transformaciones siempre han sido parte de la casa vernácula y serán parte de su evolución futura, es importante que sigan el curso de valorización de la preexistencia y con la aportación de nuevos valores que hasta el siglo XX caracterizó la evolución de la casa tradicional. La investigación científica puede ayudar a evitar riesgos, como la obliteración de elementos o demolición de ejemplares, al informar sobre modelos, estrategias y materialidades a seguir para valorar este patrimonio común a medida que sigue su trayectoria continua de evolución. 


\section{BIBLIOGRAFÍA}

- Abreu, A., Pinto Correia, T. y Oliveira, R. (2002) Contributos para a Identificação e Caracterização da Paisagem em Portugal Continental, vol. I y V. Évora: Universidade de Évora

- Bicho, S. (1999) A judiaria de Castelo de Vide: contributos para o seu estudo na óptica da conservação do património urbano. Tesis de master inédita, Universidade de Évora

- Boiça, J.M.F. (2018) Serpa na formação do Reino de Portugal 1166-1295. Serpa: Câmara Municipal

- Carmona Barrero, J.D. (2011) La casa abovedada. Evolución de los espacios domésticos tradicionales en la Baja Extremadura. Saber Popular-Revista Extremeña de Folklore, n. ${ }^{\circ} 30$, pp. $19-290$

- Cascales Barrio, J. (2017) Territorio y paisaje en la Sierra de Aracena: casas y asentamientos entre los siglos $X V$ y $X X$. Tesis doctoral inédita, Universidad de Sevilla

- Conde, M.S. (2011) Construir, Habitar: A Casa Medieval. Braga: CITCEM

- Cosme, J. (2000) A Solidariedade e a conflitualidade na fronteira portuguesa do Alentejo (Séculos XIII-XVIII). População e Sociedade, n. ${ }^{\circ}$ 6, pp. 83-100

- Cosme, J. (1992) O Reflexo das rivalidades lusocastelhanas no espaço raiano (1165-1580). O caso dos concelhos de Moura, Mourão, Olivença e Serpa. Revista de Estudios Extremeños, tomo XL VIII, n. ${ }^{\circ}$ II, pp. 377-404

- Duarte, C. y Lamas, J. (1988) Plano de Salvaguarda e Reabilitação do Centro Histórico de Moura. Moura: Câmara Municipal

- Duclos Bautista, G. (2005) Las reformas en las fortificaciones de la banda gallega y de la raya de Portugal en los siglos XVII y XVIII. En: Pérez Macías, J. (ed.) La banda gallega: conquista y fortificación de un espacio de frontera (siglos XIII-XVIII). Huelva: Universidad de Huelva, pp. 229-253

- Feria Toribio, J.M., Andrades, J.M. y Ruiz Recco, F. (2002) Redes de Centros Históricos en Andalucía. Sevilla: Consejería de Obras Públicas y Transportes, Consejería de Cultura

- Gaspar, J. (1969) A Morfologia Urbana de Padrão Geométrico na Idade Média. Finisterra, vol. IV, n. ${ }^{\circ} 8$, pp. 198-215

- Macias, S. (1993) Moura na Baixa Idade Média: elementos para um estudo histórico e arqueológico. Arqueologia Medieval, n. ${ }^{\circ}$ 2, pp. 127-157

- Macias, S. y Gaspar, V. (2005) Fortificações modernas de Moura. Moura: Câmara Municipal

- Rei, J. y Sousa Gago, A. (2018) Abobadilha Alentejana -uma técnica construtiva tradicional, RPEE-. Revista
Portuguesa de Engenharia de Estruturas, Série III, n. ${ }^{\circ}$, pp. 29

- Ribeiro, O. (1961) Geografia e Civilização-temas portugueses. Lisboa: Instituto de Alta Cultura Centro de Estudos Historicos

- Rosado, A., Liberato, M. y Costa, M. (2018) Contributo para a história da arquitectura da habitação e da organização do espaço no interior do castelo de Estremoz. En: Arqueologia Urbana em Centros Históricos-Actas IV FAUR. Faro: Universidade do Algarve, pp. 286 -304

- Rosado, A. (2019) Traditional Urban Housing at Alentejo's 'Marble Area'. En: Calatrava Escobar, J. (coord.) La casa: espacios domésticos, modos de habitar. Madrid: Adaba Editores, pp. 104-116

- Santos, J. (2014) Estudo Construtivo e Estrutural de Abóbadas Alentejanas. Tesis de master inédita, Instituto Superior Técnico/Academia Militar de Lisboa

- Trindade, L. (2009) Urbanismo na composição de Portugal. Tesis doctoral inédita, Faculdade de Letras da Universidade de Coimbra 